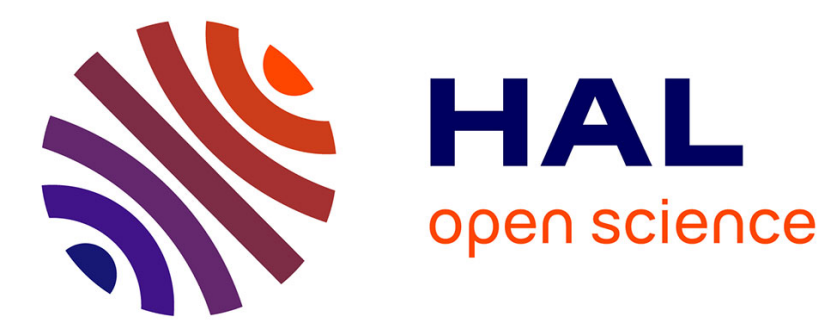

\title{
Substitution of Titanium for Magnesium Ions at the Surface of Mg-Doped Rutile
}

Céline Dupont, Jacques Jupille, Sylvie Bourgeois, Patrick Le Fèvre, Alberto Verdini, Luca Floreano, Bruno Domenichini

\section{To cite this version:}

Céline Dupont, Jacques Jupille, Sylvie Bourgeois, Patrick Le Fèvre, Alberto Verdini, et al.. Substitution of Titanium for Magnesium Ions at the Surface of Mg-Doped Rutile. Journal of Physical Chemistry C, 2020, 124 (21), pp.11490-11498. 10.1021/acs.jpcc.0c02321 . hal-03022479

\section{HAL Id: hal-03022479 \\ https://hal.science/hal-03022479}

Submitted on 24 Nov 2020

HAL is a multi-disciplinary open access archive for the deposit and dissemination of scientific research documents, whether they are published or not. The documents may come from teaching and research institutions in France or abroad, or from public or private research centers.
L'archive ouverte pluridisciplinaire HAL, est destinée au dépôt et à la diffusion de documents scientifiques de niveau recherche, publiés ou non, émanant des établissements d'enseignement et de recherche français ou étrangers, des laboratoires publics ou privés. 


\title{
Substitution of titanium for magnesium ions at the
}

\section{surface of rutile}

Celine Dupont, ${ }^{* \dagger}$ Jacques Jupille, ${ }^{\ddagger}$ Sylvie Bourgeois, ${ }^{\dagger}$ Patrick Le Fèvre, ${ }^{\text {Il }}$ Alberto Verdini, ${ }^{\S}$ Luca Floreano, ${ }^{\S}$ and Bruno Domenichini ${ }^{\dagger}$

Laboratoire Interdisciplinaire Carnot de Bourgogne (ICB), UMR 6303 CNRS, Université Bourgogne Franche-Comté, BP 47870, 21078 Dijon Cedex, France, Institut des NanoSciences de Paris, Sorbonne University and CNRS, Campus de Jussieu, F-75252 Paris, France, Synchrotron SOLEIL, L'Orme des Merisiers, BP 48, 91192 Gif-sur-Yvette, France, and Instituto Officina dei Materiali IOM-CNR, Laboratorio TASC s.s. 14 km 163.5, 34149 Trieste, Italy

E-mail: celine.dupont@u-bourgogne.fr

\begin{abstract}
The surface structure of $\mathrm{Mg}$-doped rutile $\mathrm{TiO}_{2}(011)$ surfaces is determined by combining core level/valence band photoemission and photoelectron diffraction (PED) to evolutionary algorithm, density functional theory (DFT) and multiple scattering calculations. Upon annealing the reduced crystal above $620 \mathrm{~K}, \mathrm{Mg}$ segregates by substitution to $\mathrm{Ti}$ atoms from the $\mathrm{TiO}_{2}$ lattice while keeping the known reconstruction of the $\mathrm{Mg}$-free surface. Band gap states being totally healed by $\mathrm{Mg}$ segregation, the charge compensation is provided by $\mathrm{O}$ vacancies as formally expressed by the Kröger and Vink notation. A full support to those findings comes from

\footnotetext{
*To whom correspondence should be addressed

${ }^{\dagger}$ Laboratoire Interdisciplinaire Carnot de Bourgogne (ICB), UMR 6303 CNRS, Université Bourgogne FrancheComté, BP 47870, 21078 Dijon Cedex, France

†nstitut des NanoSciences de Paris, Sorbonne University and CNRS, Campus de Jussieu, F-75252 Paris, France 'Synchrotron SOLEIL, L'Orme des Merisiers, BP 48, 91192 Gif-sur-Yvette, France

§Instituto Officina dei Materiali IOM-CNR, Laboratorio TASC s.s. 14 km 163.5, 34149 Trieste, Italy
} 
DFT calculations based on findings from evolutionary algorithm calculations which demonstrate that a combination of four surface structures nicely accounts for the observed experimental Ti 3s and Mg 2s patterns. These model structures only involve Mg in substitutional position and $\mathrm{O}$ vacancies, whereas neither interstitial atoms nor excess electrons are experimentally detected.

\section{Introduction}

Doping titanium dioxide by aliovalent cations is an actively pursued route to tailor the multiple properties of this material ${ }^{1}$. Depending on how the cation valence structure compares with that of titanium (either donor or acceptor), the doping elements modify the gap width ${ }^{2}$, change the electrical conductivity and shift the flat band potential ${ }^{3}$. In this context, the numerous applications of Aland $\mathrm{Mg}$-doped $\mathrm{TiO}_{2}$ have attracted much attention. Aluminum-doping reduces the photocatalytic activity of $\mathrm{TiO}_{2}$ pigments by widening the band gap and trapping the photogenerated charges ${ }^{4}$. Both $\mathrm{Mg}-\frac{5}{\sqrt{9}}$ or Al-doped ${ }^{10} \mathrm{TiO}_{2}$ improve the performances of dye-sensitised solar cells through the increase of the open circuit voltage $\frac{10}{}$. Similarly, $\mathrm{Mg}$-doped $\mathrm{TiO}_{2}$ electron transport layers improve the efficiency of perovskite solar cells 11 . The reversible intercalation of multivalent $\mathrm{Mg}^{2+}$ and $\mathrm{Al}^{3+}$ ions in anatase with a high concentration of cation (Ti) vacancies was brought forward as a proof of concept for increasing the volumetric energy densities in multivalent batteries $\frac{12}{\text {. Fi- }}$ nally, Mg-doped titanium dioxide is frequently used to promote photocatalytic reactions such as photoreduction of $\mathrm{CO}_{2} \frac{13}{}$, oxidation of $\mathrm{NO}^{14}$ and photodegradation $15 \sqrt{16}$.

The $\mathrm{Al}$ and $\mathrm{Mg}$ insertion modes are quite similar. Both elements are suggested to occupy substitutional sites accompanied by oxygen vacancies for charge compensation, hence preserving the

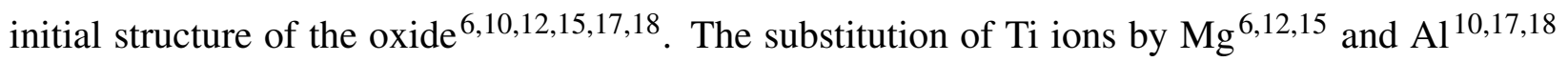
ions in the $\mathrm{TiO}_{2}$ lattice is favored by the similarity of the ionic radius of $\mathrm{Al}^{3+}(0.53 \AA)$ and $\mathrm{Mg}^{2+}$ $(0.72 \AA)$ with that of $\mathrm{Ti}^{4+}(0.68 \AA)^{19}$. Regarding electronic properties, pristine titanium dioxide can be easily reduced to a n-type semiconductor through the formation of both oxygen vacancies 
and titanium interstitials ions 20 . Those two types of intrinsic point defects generate excess electrons that populate the Ti $3 \mathrm{~d}$ band gap states $(\mathrm{BGS})^{21}$ located within the band gap at about $0.8 \mathrm{eV}$ below the Fermi level as observed experimentally $22-26$ and modeled by hybrid DFT calculations 27 . Substitution of Ti atoms by $\mathrm{Al}$ atoms is predicted to heal the band gap states $10|17| 18$. Owing to the importance of the topic, a variety of techniques focused on the impact of doping on the crystallographic and electronic structure of the oxide, including x-ray absorption ${ }^{28}$, x-ray scattering ${ }^{12}$, electron paramagnetic resonance ${ }^{28 \mid 29}$ and nuclear magnetic resonance ${ }^{12}$. However, despite intensive efforts, the still vivid debate on the actual doping element/vacancy ratio and on the occurrence

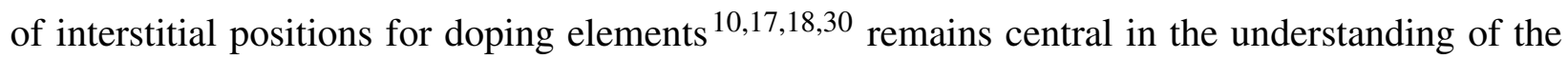
crystallography of doped oxides, the subject being further complicated by the sensitivity of the actual properties of doped $\mathrm{TiO}_{2}$ to synthesis conditions $\frac{8[10[12}{\text {. }}$.

Quite efficient for investigating bulk properties, the aforementioned methods are hardly relevant to analyze the extreme surface of the solids which plays an important role in many applications. For example, surface structure is a key parameter in catalysis and photocatalysis and in dye-sensitized and perovskite solar cells in which it drives charge transfer. The present work takes up the challenge of the analysis of the surface defect states of $\mathrm{Mg}$-doped $\mathrm{TiO}_{2}(011)$ rutile. Besides, whereas the bulk structure of Al-doped $\mathrm{TiO}_{2}$ has been abundantly studied ${ }^{10[17] 18}$, the Mgdoped one has never been investigated. We combine herein experimental data - surface sensitive core level and valence band photoemission and resonant photoelectron diffraction (PED) experiments - with a theoretical analysis based on evolutionary algorithm, density functional theory (DFT) and multiple scattering calculations. Resonant PED experiments supported by calculations have proven to be an extremely relevant tool to determine the structure of the rutile $(110)^{31 / 32}$ and $(011)^{33}$ surface regions. The technique shows a great sensitivity to small defects concentrations, thanks to the enhancement of the Ti $3 \mathrm{~d}$ emission through the resonant valence-band photoemission process $31 / 32$. At the Ti $L_{2,3}$ edge, the direct photoemission from the valence-band states (with the Ti 3d character) overlaps and interferes with the Auger-like autoionization process, in particular 
with the participator decay channel that leads to the same final state of a VB photoemission $34-36$. Of particular interest in the case under study, PED could demonstrate that the defective Ti $3 \mathrm{~d}$ sites mostly lie on the subsurface layers of the rutile $\mathrm{TiO}_{2}(110)$ surface $\frac{31 / 32}{\text {, a result latter supported }}$ by an electron energy loss study of the origin and depth profile of band gap states (BGS) ${ }^{21}$. Such an ability to probe the existence and localization of excess electrons is central in the present work which aims to examine (i) the surface structure of a $\mathrm{Mg}$-doped rutile $\mathrm{TiO}_{2}(011)$ crystal, (ii) the mode of insertion of $\mathrm{Mg}$ atoms and (iii) the behavior of the excess electrons in the presence of the doping element.

\section{Methods}

\section{Experimental}

The experiments were performed at the ALOISA beamline $e^{37}$ of the Elettra Synchrotron Light Source in Trieste, Italy, in an ultra-high vacuum chamber (base pressure $10^{-10} \mathrm{mbar}$ ) that has already been described $31 / 37$. We used a $\mathrm{TiO}_{2}(011)$ crystal (SurfaceNet $\mathrm{GmbH}$ ) doped by magnesium that could easily segregate by annealing. This single sample, which contains magnesium as random impurity, offers the opportunity to explore the surface structure of a doped oxide. The amount of magnesium is below the detection limit of this element by electron microprobe analysis (ca. 1\%). It was carefully checked by photoemission that no other impurity appeared during the experiments. The sample was prepared under vacuum through cycles of argon ion bombardment ( $1 \mathrm{keV}, 30 \mathrm{~min})$ followed by annealing at different temperatures. For photoemission and PED experiments, the Xray beam was impinging the sample at grazing incidence $\left(4^{\circ}\right)$ with light polarization normal to the surface. Surface analysis was performed by photoemission from the $\mathrm{Mg} 2 \mathrm{p}$ and $\mathrm{Ti} 3 \mathrm{p}$ levels at a primary photon energy of $140 \mathrm{eV}$. This energy allows (i) a relatively larger sensitivity to $\mathrm{Mg}$ rather than to $\mathrm{Ti}$, thanks to the favorable photoionization cross section of $\mathrm{Mg} 2 \mathrm{p}$ (3.4 Mbarn) compared to that of Ti 3 p (1.2 Mbarn) ${ }^{38}$ and (ii) the best surface sensitivity due to an electron escape depth 
as short as $\sim 5 \AA$ for both $\mathrm{Mg} 2 \mathrm{p}$ and $\mathrm{Ti} 3 \mathrm{p}$ photoelectrons. Instead, to study the valence band in conditions allowing the resonant enhancement of the Ti $3 \mathrm{~d}$ defect states, the chosen photon energy was $462.5 \mathrm{eV}$. It corresponds to the $\mathrm{Ti}_{2}$ threshold, as determined by XANES measurements 35 . We performed PED measurements on the Mg-doped rutile crystal by recording the $\mathrm{Mg} 2 \mathrm{~s}$ and $\mathrm{Ti}$ 3s core levels intensities as a function of polar and azimuthal angles. Even if the cross sections of these levels are smaller than those of the corresponding $\mathrm{p}$ levels, experimental values of the peak area are easier to extract since the quantitative analysis of the area of the $\mathrm{Mg} 2 \mathrm{p}$ spectral line requires to subtract the Ti $3 p$ shake up satellite that is superposed to it (see Figure 1). The kinetic energies for the PED experiments were $428 \mathrm{eV}$ and $455 \mathrm{eV}$, for the $\mathrm{Mg}$ 2s and the $\mathrm{Ti}$ 3s lines, respectively. All measurements were done at room temperature.

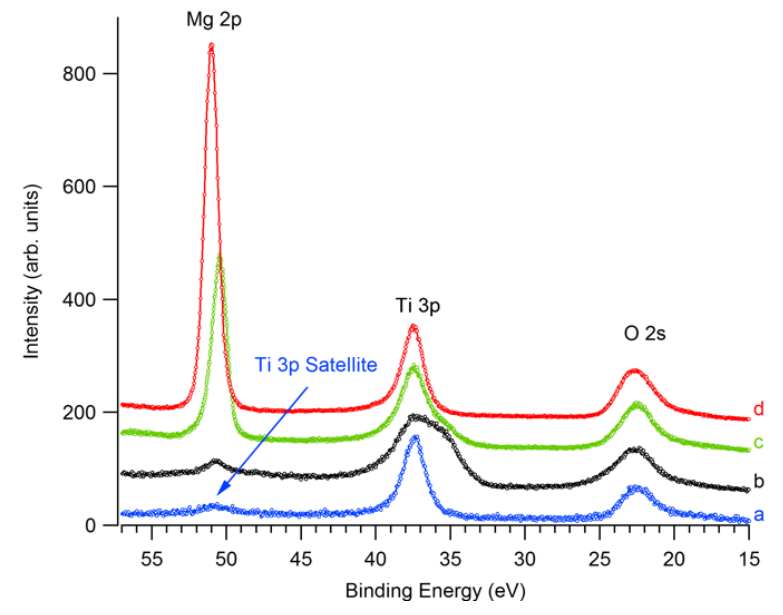

Figure 1: Photoemission spectra recorded at a photon energy of $140 \mathrm{eV}$ over the binding energy range corresponding to the $\mathrm{Mg} \mathrm{2p}$, Ti $3 \mathrm{p}$ and $\mathrm{O} 2 \mathrm{~s}$ core levels, for surfaces of different rutile $\mathrm{TiO}_{2}(011)$ samples: (a) Mg-free crystal sputtered and annealed at $870 \mathrm{~K}$; (b) Mg-doped crystal after sputtering; (c) same as (b) after annealing at $620 \mathrm{~K}$ for 3 minutes; (d) same as (b) annealed at $870 \mathrm{~K}$ for 3 minutes.

PED patterns were recorded by scanning the azimuthal angle $\phi$ over $110^{\circ}$ including both symmetry directions $[01 \overline{1}]$ and $[00 \overline{1}]$. The polar angle $\theta$ was varied from -2 to $80^{\circ}$, where $0^{\circ}$ corresponds to the direction normal to the surface. The step size was $2^{\circ}$ for both $\phi$ and $\theta$. In order to obtain the full $\phi$ range of $360^{\circ}$, the measured patterns were folded symmetrically according to the C2v point symmetry of the surface. The symmetry was checked for Ti $2 p$ PED with a few wider $\phi$ 
scans. The PED patterns are reported as $\chi$ functions with:

$$
\chi(\theta, \phi)=\frac{I(\theta, \phi)-I_{0}(\theta)}{I_{0}(\theta)}
$$

where $I_{0}(\theta)$ is given by the $\phi$-average of the photoemission intensity $I(\theta, \phi)$ measured at polar angle $\theta$ and azimuth $\phi$ and represents the non-diffractive contribution 39 .

To analyse the difference between two patterns $\chi_{A}$ and $\chi_{B}$, we used the structure reliability factor, $\mathrm{R}_{f}$, defined as:

$$
R_{f}=\sum\left(\chi_{A}-\chi_{B}\right)^{2} / \sum\left(\chi_{A}^{2}+\chi_{B}^{2}\right)
$$

where the sum is performed over the whole experimental angular ranges. $R_{f}=0$ and $R_{f}=1$ correspond to identical and uncorrelated datasets, respectively.

\section{Computational details}

DFT calculations have been used to model and optimize the structure of Mg-doped rutile, before the PED modeling. However, considering the numerous possibilities for $\mathrm{Mg}$ doping in the $\mathrm{TiO}_{2}(011)$ crystal, a comprehensive human screening appears as a huge and waste of time undertaking. Starting with compositions deduced from XPS experiments, we used the evolutionary algorithm implemented in USPEX ${ }^{40}-43$ in combination with total energy DFT calculations through the VASP code $\sqrt[4445]{4}$ to determine the structure of doped rutile. Evolutionary algorithm calculations were performed through fixed compositions calculations using the surface method implemented in USPEX, with the system divided in substrate, buffer and surface regions. In agreement with experimental results, $\mathrm{Mg}$ atoms were included only in the surface region. Seeds structures derived from the rutile $\mathrm{TiO}_{2}(011)$ reconstruction previously published ${ }^{33}$ were also included.

The most stable structures given by USPEX were then optimized at higher accuracy with VASP, following the conditions we already published 33 . In particular the system was modeled by symmetric slabs of 11 layers, with reconstruction and $\mathrm{Mg}$ on both sides. Total energy calculations

were performed at the GGA+U level with the $\mathrm{PBE}^{46}$ functional and $\mathrm{U}_{\text {eff }}=4.2 \mathrm{eV}$ in the $\mathrm{Du}$ - 
darev's approach $\frac{47}{4}$. The projector augmented-wave (PAW) method has been used, with twelve valence electrons for Ti (namely, $3 s^{2} 3 p^{6} 4 s^{2}$ and $3 d^{2}$ ), six for $\mathrm{O}$ (namely, $2 s^{2}$ and $2 p^{4}$ ), and two for $\mathrm{Mg}$ (namely, $3 \mathrm{~s}^{2}$ and $3 \mathrm{p}^{0}$ ) and a converged plane-wave cutoff of $500 \mathrm{eV}$ has been applied. A $3 \times 3 \times 1$ Monkhorst-Pack ${ }^{48}$ k-point mesh was used to sample the first Brillouin zone. The geometry optimization was completed when forces were smaller than $0.01 \mathrm{eV}^{-1}$. PED patterns of the best candidates, namely the most stable, were then modeled by performing multiple scattering calculations using the EDAC code ${ }^{49}$, within the cluster approach.

\section{Results and Discussion}

\section{Reoxidation of the rutile surface}

Photoemission spectra involving the $\mathrm{Mg} 2 \mathrm{p}$, Ti $3 \mathrm{p}$ and $\mathrm{O} 2 \mathrm{~s}$ core levels and the corresponding valence band region are shown in Figures 1 and 2, respectively. Spectra recorded on the Mg-free $\mathrm{TiO}_{2}(011)$ crystal prepared in similar conditions as the Mg-doped rutile sample are shown in both figures for comparison (bottom (a) curves). Upon sputtering the $\mathrm{Mg}$-doped $\mathrm{TiO}_{2}(011)$ crystal, a Mg-free surface is obtained confirming the very low concentration of $\mathrm{Mg}$ in the material. The strong component seen on the lower binding energy side of the Ti $3 p$ line stems from the reduced Ti atoms whose formation goes with the appearance of oxygen vacancies (Figure 1(b)). Mg segregates after a mild annealing at $620 \mathrm{~K}$ for 3 minutes (Figure 1(c)). Subsequent annealing at temperatures higher than $870 \mathrm{~K}$ for 3 minutes (Figure 1(d)) leads to additional Mg segregation. Owing to the proximity of the binding energies of the two levels, escape depths were judged similar. The Ti 3p binding energy of $37.4 \mathrm{eV}$ is similar to that of stoichiometric $\mathrm{TiO}_{2}$. The binding energy of $\mathrm{Mg}$ $2 \mathrm{p}$ is $50.5 \mathrm{eV}$ for the annealing at $620 \mathrm{~K}$ and $50.9 \mathrm{eV}$ for the magnesium richest surface obtained

after annealing at $870 \mathrm{~K}$. Both values are close to that found for oxidized $\mathrm{Mg}$. The shifted Ti $3 p$ component, which is associated with a reduction of the oxide, decreases in intensity upon annealing at $620 \mathrm{~K}$ (Figure 1(c)). It is no longer observed after annealing at $870 \mathrm{~K}$ (Figure11(d)).

Spectra of the valence band region are shown in Figure 2 at the excitation energy of the Ti $L_{2}$ 


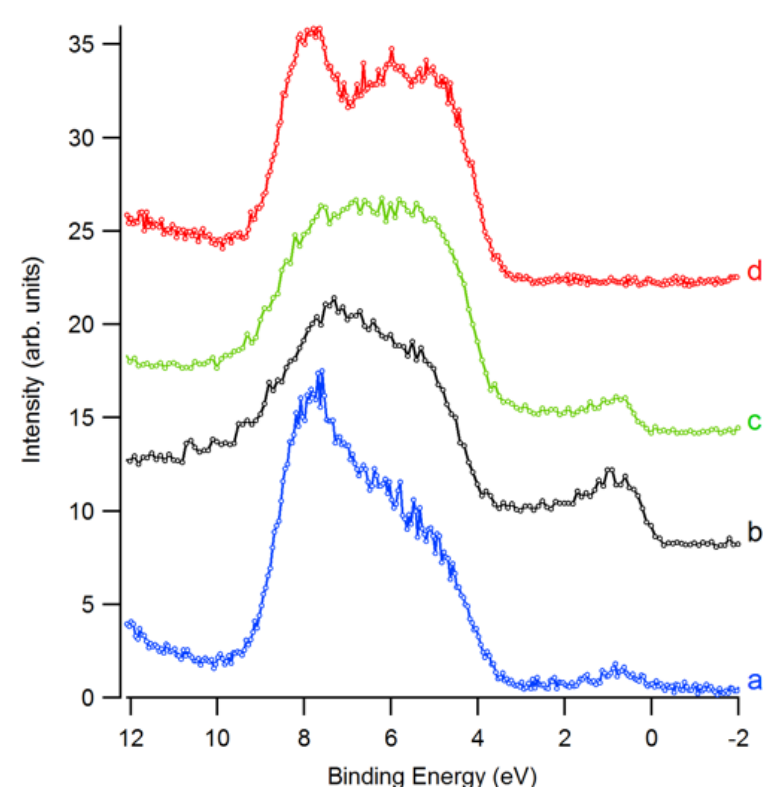

Figure 2: Spectra of the valence band region on the same rutile $\mathrm{TiO}_{2}(011)$ surfaces as in Figure 1 . Spectra are recorded at $462.5 \mathrm{eV}$ i.e. at Ti $2 \mathrm{p} \rightarrow \mathrm{Ti} 3 \mathrm{~d}$ threshold in order to enhance the band gap state (see text).

edge (on-resonance) for higher sensitivity to the band gap state (BGS). As a result of argon ion sputtering the $\mathrm{TiO}_{2}(011)$ surface, a Ti 3d BGS appears at a binding energy of $\sim 0.8 \mathrm{eV}$ (Figure 2(b)), as commonly observed in photoemission spectra of defective rutile surfaces $22-25$. The BGS (Figure 2(b)) and the Ti 3p lower binding energy shift ${ }^{51}$ are both fingerprints of the reduction of the oxide which is formally expressed by $\mathrm{Ti}^{4+} \rightarrow \mathrm{Ti}^{n+}$ with $\mathrm{n}<4$. Upon annealing the ion-bombarded Mg-doped sample, Mg segregates within the surface layers (Figures 1(c) and (d)). In addition, the feature associated with the Ti $3 \mathrm{~d}$ states in the valence spectra decreases (Figures 2(c) and (d)). It even totally disappears at $870 \mathrm{~K}$ for the $\mathrm{Mg}$ richest surface. In this case, the $\mathrm{Ti} 3 \mathrm{~d}$ level is totally empty which means that, in the layers probed by the photoemission analysis, the Ti atoms have been fully reoxidized and are only in the $\mathrm{Ti}^{4+}$ oxidation state. Finally, it should be noticed that in the case of pristine rutile, the reoxidation of the reduced surface via the inward diffusion of interstitial titanium ions occurs rapidly above $740 \mathrm{~K}^{52}$. Therefore, the fast healing of the BGS observed at a temperature as low as $620 \mathrm{~K}$ at the surface of the $\mathrm{Mg}$-doped $\mathrm{TiO}_{2}$ is likely associated to the surface segregation of $\mathrm{Mg}$. 


\section{Localization of magnesium atoms}

Determining the position of $\mathrm{Mg}$ atoms in the structure consists in refining, at the atomic scale, the structure of the topmost layers by combining experimental results and multiple scattering simulations with a theoretical approach based on DFT calculations, as we already did for determining the reconstruction of undoped $\mathrm{TiO}_{2}(011)^{33}$. Many parameters have to be taken in account: proportion of $\mathrm{Ti}$ atoms substituted by $\mathrm{Mg}$ atoms, distribution and positions of these $\mathrm{Mg}$ atoms in the surface layers, distribution of oxygen vacancies $\left(\mathrm{O}_{v a c}\right)$ related to the presence of $\mathrm{Mg}$ atoms as well as structural relaxations due to substituted cations and $\mathrm{O}_{v a c}$. As it is impossible to carry out an exhaustive study of all cases, some assumptions must be made. The choice of the refined structure will be guided by the quantitative analysis of the experimental data and the energy of the calculated structures, as determined by DFT.

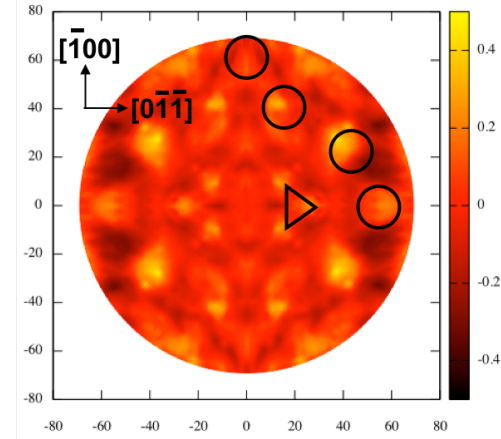

(a) Ti 2p

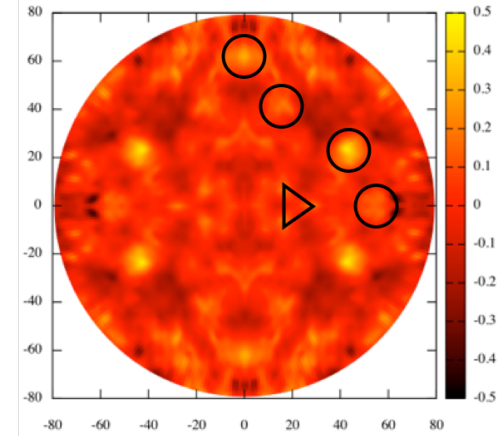

(b) $\mathrm{Ti} 3 \mathrm{~s}$

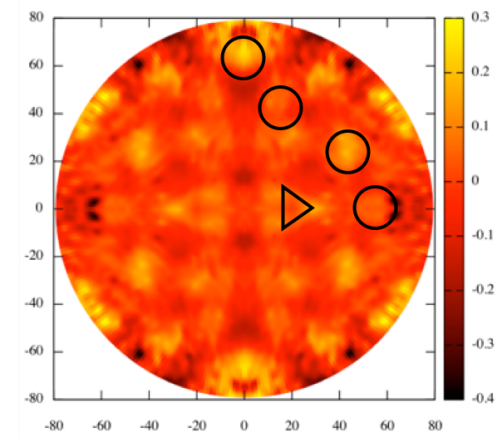

(c) $\mathrm{Mg} 2 \mathrm{~s}$

Figure 3: PED patterns of (a) the $\mathrm{Ti} 2 \mathrm{p}$ level of the $\mathrm{Mg}$-free $\mathrm{TiO}_{2}(011)$ crystal ${ }^{33}$ measured at a kinetic energy of $464 \mathrm{eV}$, (b) the $\mathrm{Ti} 3 \mathrm{~s}$ and (c) the $\mathrm{Mg}$ 2s levels of the Mg-doped crystal after annealing to $870 \mathrm{~K}$, measured at kinetic energies of 455 and $428 \mathrm{eV}$, respectively. The projection is linear, with the polar angle $\theta=0^{\circ}$ along the surface normal. The azimuth $\phi=0{ }^{\circ}$ is found at 3 o'clock along $\left\langle\overline{1} 00>\right.$ and $\phi=90^{\circ}$ is found at 12 o'clock along $<0 \overline{1} \overline{1}>$. The main well-defined spots of the Ti 3s pattern have been surrounded by circles and triangles which were then applied without change on the Ti $2 \mathrm{p}$ and $\mathrm{Mg}$ 2s patterns. (Ti 3s was taken as reference because it can be compared to both the $\mathrm{Mg} 2 \mathrm{~s}$ pattern recorded on the same doped crystal and to the Ti 2p pattern from the Mg-free crystal.)

We start the analysis by comparing the Ti 2p PED pattern measured on the $\mathrm{Mg}$-free $\mathrm{TiO}_{2}(011)$ crystal (Figure 3(a)) with the PED patterns measured on the Mg-doped sample at the Ti 3s (see Figure 3(b)) and Mg 2s (Figure 3(c)) levels. A simple visual inspection reveals that the three ex- 
perimental patterns share many features. We highlighted the main features of the Ti $3 \mathrm{~s}$ pattern on the Mg-doped crystal by drawing a set of circles and triangles (Figure 3(b)). The same set of markers is rigidly superimposed to the $\mathrm{Ti} 2 \mathrm{p}$ and $\mathrm{Mg}$ 2s PED patterns of the undoped and $\mathrm{Mg}$ doped crystals, respectively. From the strong similarity of the main diffraction features (in terms of intensity and angular position), one can infer (i) that the lattice structure of Ti in the topmost layers is practically unaffected by the $\mathrm{Mg}$ atoms and (ii) that $\mathrm{Mg}$ atoms are mostly present in the $\mathrm{TiO}_{2}$ topmost layers as substitutional ions. In particular, the characteristic reconstruction of the $\mathrm{Mg}$-free $\mathrm{TiO}_{2}(011)$ surface ${ }^{33}$, which gives rise to the three spots at the vertex of the triangles, is preserved in the Mg-doped crystal. Therefore, we may assume the reconstruction of the $\mathrm{Mg}$-free $\mathrm{TiO}_{2}(011)$ surface ${ }^{33}$ as a reference starting model for further refinement of the Mg-doped surface. Additionally, the anisotropy scales (Figures 3(b) and (c)) indicate that the amplitude of the anisotropy $\chi$ of $\mathrm{Mg} 2 \mathrm{~s}$ is about half that of $\mathrm{Ti} 3 \mathrm{~s}$. The observation suggests that $\mathrm{Mg}$ atoms may sit in a less ordered local environment than the Ti atoms or in a part of the material where the diffraction contribution originated by forward scattering is weaker, which points to the very topmost layers. We may thus assume that $\mathrm{Mg}$ atoms are distributed over a few cationic layers only, allegedly a maximum of three.

In order to estimate the amount of $\mathrm{Mg}$ atoms distributed in the upper layers, we first considered a quantitative study of the photoemission spectra at 140 and $462.5 \mathrm{eV}$. A simple analysis of the ratio $\mathrm{Mg}$ 2s/Ti 3s from the intensities of the components determined by photoemission does not allow the determination of the exact number of $\mathrm{Mg}$ atoms substituting Ti. Indeed, an atom in the topmost layer yields a larger photoemission contribution than an atom of deeper layers. In other words, a single experimental ratio $\mathrm{Mg} 2 \mathrm{~s} / \mathrm{Ti} 3 \mathrm{~s}$ can be modeled in multiple different ways. If we assume that $\mathrm{Mg}$ atoms are mostly distributed in the three topmost cationic layers, as suggested by the amplitude of the PED anisotropy, several distributions (Table 1) might be derived from the measured experimental ratios on the basis of the tabulated photoionization sections and of the inelastic mean free paths (IMFP) of the electrons - taken identical for Mg 2s and $\mathrm{Ti} 3 \mathrm{~s}$ insofar as their kinetic energy differs by only a few percent. This approach allows us to determine that between eight 
and twelve magnesium atoms are spread over the two or three first layers. To confirm this result, similar simulations have been done for the $\mathrm{Mg} 2 \mathrm{p} / \mathrm{Ti} 3 \mathrm{p}$ ratio measured for a much lower exciting photon energy $(140 \mathrm{eV})$, thus yielding an analysis much more sensitive to the surface. Here again, distributions with a rate of $\mathrm{Mg}$ between eight and twelve atoms are obtained (Table 1 ).

Table 1: $\mathrm{Mg} / \mathrm{Ti}$ ratios calculated as a function of the number of $\mathrm{Mg}$ atoms spread over the two or three first layers. $\mathrm{Mg} 2 \mathrm{p}$ and Ti 3p are analyzed with a $140 \mathrm{eV}$ photon source and $\mathrm{Mg} 2 \mathrm{~s}$ and Ti 3s with photon energy of $462.5 \mathrm{eV}$. Possible configurations - those with a deviation below $25 \%$ - are highlighted.

\begin{tabular}{c||c|c||c|c}
\multicolumn{1}{c||}{} & \multicolumn{4}{c}{$\mathrm{Mg} / \mathrm{Ti}$ ratio } \\
\hline \multicolumn{1}{c||}{} & \multicolumn{2}{c}{$\mathrm{Mg}$ 2p/Ti 3p $=3.11$} & \multicolumn{2}{c}{$\mathrm{Mg} 2 \mathrm{~s} / \mathrm{Ti} 3 \mathrm{~s}=0.66$} \\
\hline $\begin{array}{c}\text { number of } \\
\text { Mg spread }\end{array}$ & $\ldots$ 3 planes & $\ldots$ 2 planes & $\ldots$ 3 planes & $\ldots$ 2 planes \\
on ... & {$[22$ Ti sites] } & {$[14$ Ti sites] } & {$[22$ Ti sites] } & {$[14$ Ti sites] } \\
\hline 1 & 0.16 & 0.21 & 0.04 & 0.05 \\
2 & 0.34 & 0.44 & 0.09 & 0.11 \\
3 & 0.54 & 0.71 & 0.14 & 0.17 \\
4 & 0.76 & 1.01 & 0.19 & 0.23 \\
5 & 1.00 & 1.35 & 0.25 & 0.30 \\
6 & 1.26 & 1.74 & 0.31 & 0.37 \\
7 & 1.55 & 2.19 & 0.37 & 0.45 \\
8 & 1.89 & 2.73 & 0.44 & 0.54 \\
9 & 2.26 & 3.38 & 0.51 & 0.63 \\
10 & 2.69 & 4.16 & 0.59 & 0.73 \\
11 & 3.20 & 5.15 & 0.68 & 0.85 \\
12 & 3.76 & 6.40 & 0.77 & 0.97 \\
13 & 4.43 & 7.38 & 0.87 & 1.07
\end{tabular}

Following results of Table 11, we have performed different USPEX calculations for the five concentrations of $\mathrm{Mg}$, spread over the three upper layers. The most stable structure presents a surface energy of $76 \mathrm{meV} / \AA^{2}$ with a $\mathrm{Mg}$ concentration of nine atoms spread over the two topmost layers of the simulation cell. Considering that the thermal energy is approximatively $20 \mathrm{meV}$ at room temperature, our operating condition, all structures presenting a surface energy lower than $100 \mathrm{meV} / \AA^{2}$ are considered as realistic. This criterium discards all structures with ten or more magnesium atoms. Thus there remain only fifteen structures presenting a surface energy below $100 \mathrm{meV} / \AA^{2}$ with either eight or nine $\mathrm{Mg}$ atoms.

For this final set of energy favored configurations, we calculated the PED patterns and we evaluated 
the corresponding structural reliability factor $\left(\mathrm{R}_{f}\right)$. We first considered the Ti 3s PED diagram to discriminate among the possible configurations. The final $\mathrm{R}_{f}$ is optimized by considering all possible combinations of the fifteen structures. With this last refinement, only the four structures reported in Figure 4 are retained to appear in the final description. Hence a single model cannot be drawn for $\mathrm{Mg}$-doped $\mathrm{TiO}_{2}(001)$, but rather a family of four configurations, each one with eight $\mathrm{Mg}$ atoms spread over the two first layers, whereas all structures with nine $\mathrm{Mg}$ atoms have been discarded because they do not yield any optimization of the overall $\mathrm{R}_{f}(\mathrm{Ti} 3 \mathrm{~s})$. This combination of structures, weighted as reported in Table 2, leads to $\mathrm{R}_{f}(\mathrm{Ti} 3 \mathrm{~s})=0.69$ and $\mathrm{R}_{f}(\mathrm{Mg} 2 \mathrm{~s})=0.61$. According to the DFT models, these structural configurations involve six $\mathrm{Ti}$ atoms and eight $\mathrm{Mg}$ atoms in substitutional positions over the first two layers. With respect to the defect-free rutile structure, it corresponds to twenty $\mathrm{O}$ atoms or, in other word, to eight $\mathrm{O}_{v a c}$ corresponding to a percentage of $29 \%$.

Table 2: Surface energy (in meV/ $\AA^{2}$ ), $\mathrm{R}_{f}$ for Ti $3 \mathrm{~s}, \mathrm{R}_{f}$ for $\mathrm{Mg} 2 \mathrm{~s}$ and contribution (in $\%$, with an uncertainty of $\pm 1 \%$ ) in the final structure of the four retained configurations. Averaged values are given for the final configuration.

\begin{tabular}{l||c|c|c|c} 
& $\mathrm{E}\left(\mathrm{meV} / \AA^{2}\right)$ & $\mathrm{R}_{f}(\mathrm{Ti} 3 \mathrm{~s})$ & $\mathrm{R}_{f}(\mathrm{Mg} 2 \mathrm{~s})$ & Contribution (\%) \\
\hline \hline Structure (a) & 89 & 0.71 & 0.66 & 50 \\
\hline Structure (b) & 95 & 0.77 & 0.81 & 20 \\
\hline Structure (c) & 97 & 0.74 & 0.56 & 15 \\
\hline Structure (d) & 98 & 0.74 & 0.78 & 15 \\
\hline \hline Combination & 93 & 0.69 & 0.61 &
\end{tabular}

The simulated PED patterns of the Ti 3s and Mg 2s levels obtained with the optimal combination defined in Table 2 are reported in Figure 5 together with the experimental patterns, as taken from Figure 3. Sets of circles, ovals and triangles are used to highlight the main features of the experimental patterns. For both atomic species, the position of spots on the simulated patterns almost perfectly reproduce the experimental features. The disagreements mostly come from missing spots, like that marked with a blue cross in the case of $\mathrm{Mg} 2 \mathrm{~s}$. This means that the selected structures (Figure 4) fairly represent the actual positions of $\mathrm{Ti}$ and $\mathrm{Mg}$ atoms and only few $\mathrm{Mg}$ atoms escape our structural analysis. 


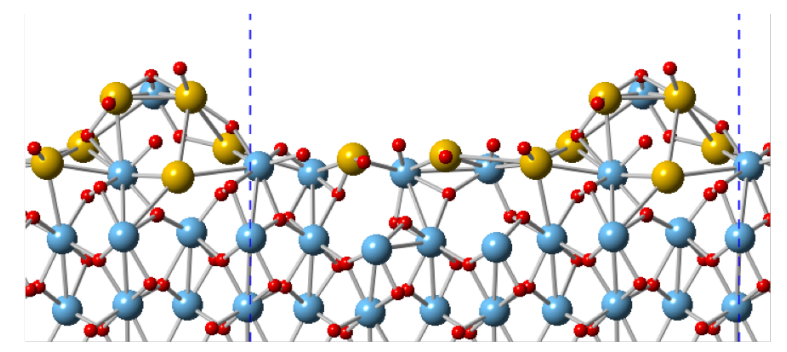

(a)

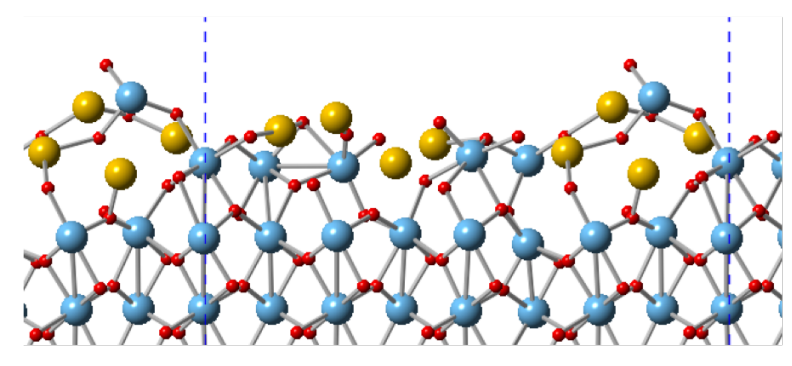

(c)

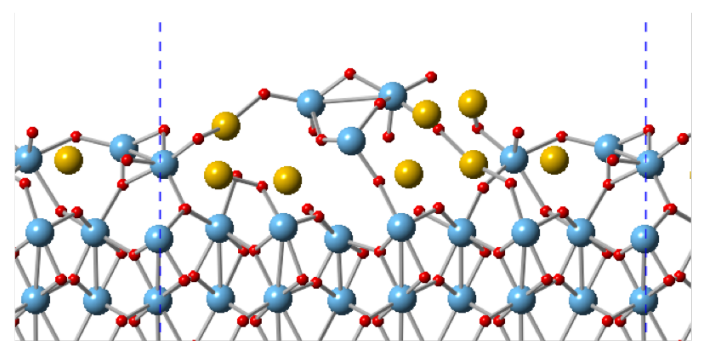

(b)

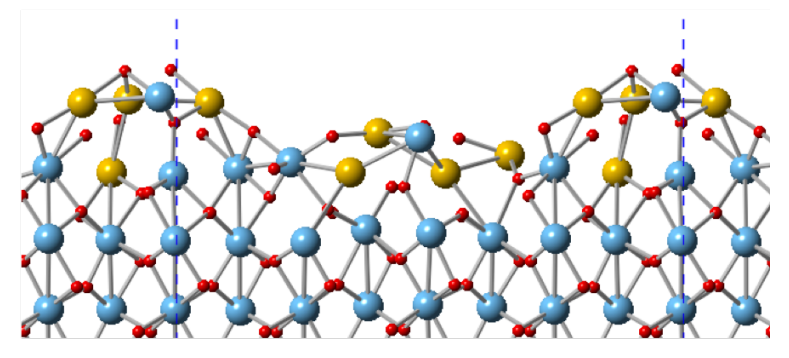

(d)

Figure 4: Sideviews of the top layers of the four different structures contributing to the experimental $\mathrm{Mg}$-doped $\mathrm{TiO}_{2}(011)$. Ti atoms are reported in blue, $\mathrm{Mg}$ atoms in yellow and $\mathrm{O}$ atoms in red. Dashed blue lines stand for the limit of the periodic simulation cell.

\section{Involved processes}

The surface structure and composition of a $\mathrm{Mg}$-doped rutile $\mathrm{TiO}_{2}(011)$ crystal are unambiguously determined. We observe the same surface reconstruction as on the pristine crystal. Besides the initial rutile lattice, the surface termination only involves doping $\mathrm{Mg}$ atoms in substitutional positions and oxygen vacancies for charge compensation. The presence of excess electrons and interstitial atoms $(\mathrm{Mg}$ or $\mathrm{Ti})$ is discarded in the limit of accuracy of our experimental data and confirmed by the calculated structures.

At the surface of the reduced $\mathrm{Mg}$-doped $\mathrm{TiO}_{2}(011), \mathrm{Mg}$ segregation brings into play quantities of $\mathrm{Mg}$ that go well beyond the defect concentration of less than ten percent $\frac{53}{\sqrt{3}}$ since the estimated population of oxygen vacancies created by the $\mathrm{Mg}$ segregation amounts to $29 \%$ of the oxygen atoms involved in the lattice of the pristine oxide. Formally, this suggests two mechanisms which both lead to the segregation of magnesium and the formation of oxygen vacancies, such that one of these mechanisms totally heals the excess electrons that are present at the reduced oxide surface 
Experiment

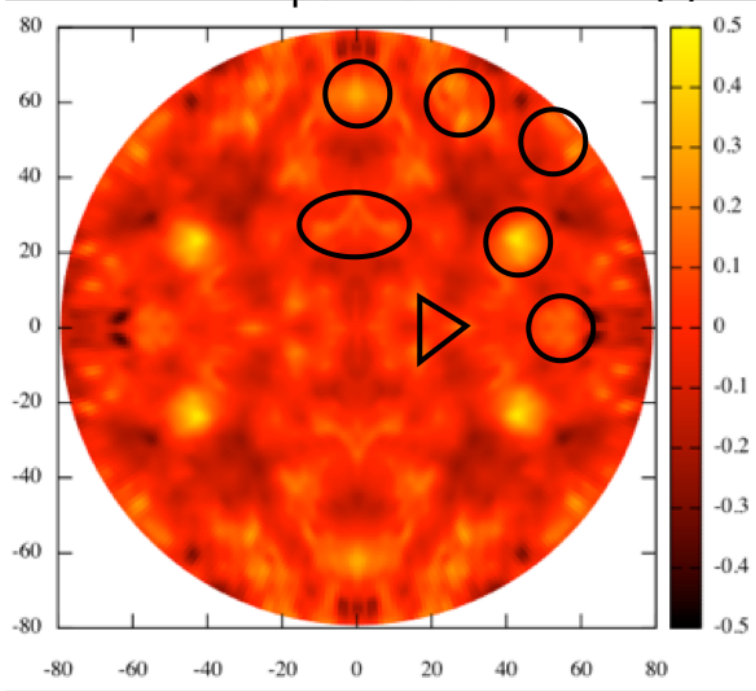

Experiment

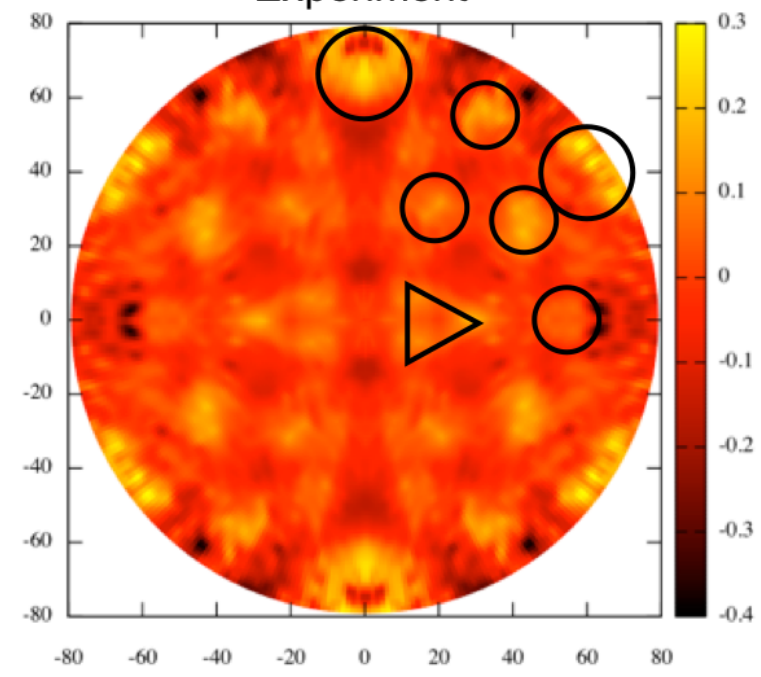

Simulation

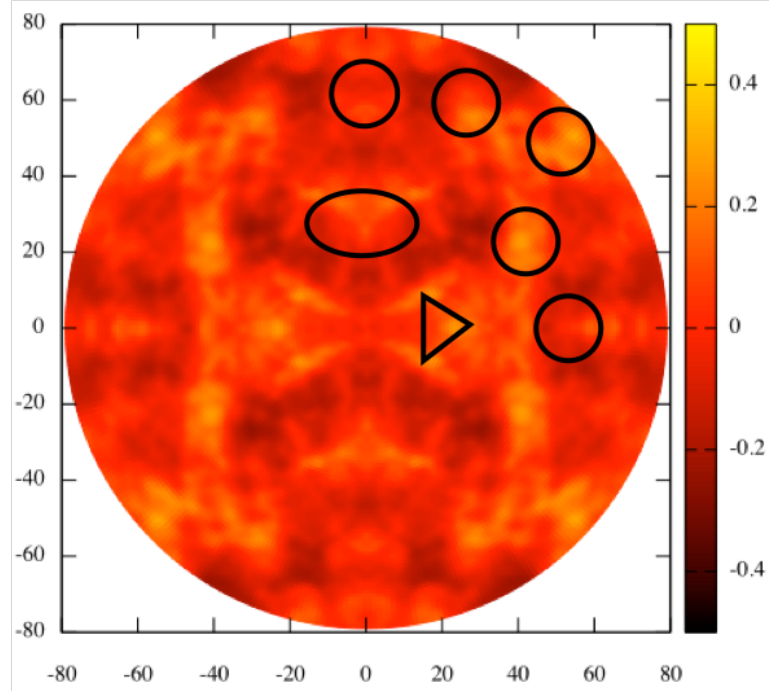

(b) PED Mg 2s

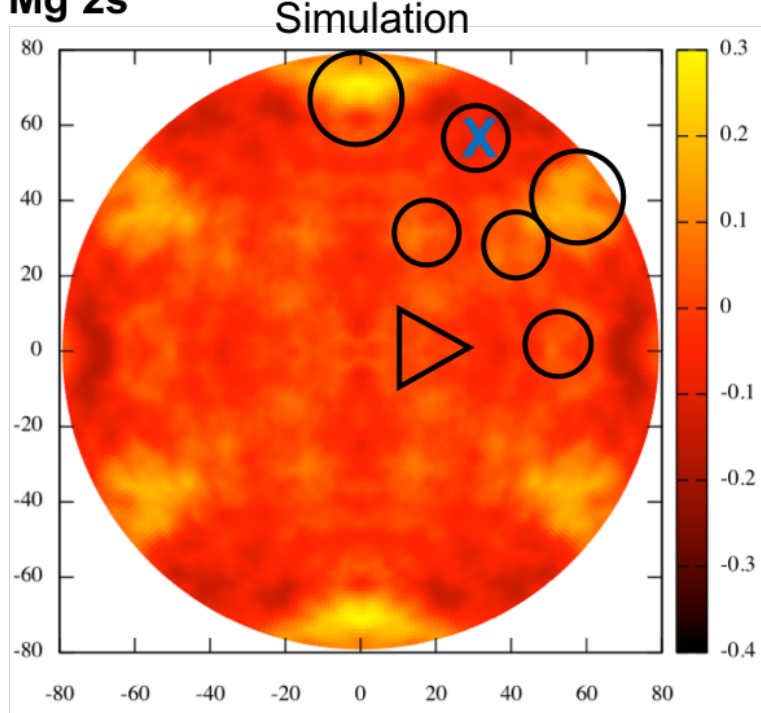

Figure 5: Comparison of the experimental patterns of the (a) Ti 3s (kinetic energy of $455 \mathrm{eV}$ ) and (b) $\mathrm{Mg} 2 \mathrm{~s}$ (kinetic energy of $428 \mathrm{eV}$ ) levels of the $\mathrm{Mg}$-doped $\mathrm{TiO}_{2}(011)$ structure to the simulated patterns obtained by combination of the four configurations reported on Figure 4 . In both cases, the main spots of the experimental patterns have been highlighted by circles, ovals and triangles whose sets have been rigidly superimposed to the simulated patterns. 
(Figure 2) while the other simply gives rise to oxygen vacancies. That chemistry can be expressed by applying the Kröger and Vink notation ${ }^{54}$ to denote charges and lattice sites as well as intrinsic defect formation reactions, involving atoms in lattice sites $\left(O_{O}\right.$ and $\left.T i_{T i}\right)$, non-ionized oxygen vacancies $\left(V_{O}^{\bullet \bullet}\right)$, titanium ions in interstitial sites $\left(T i_{i}^{\bullet \bullet \bullet \bullet}\right)$ and $\mathrm{Mg}$ atoms substituted to $\mathrm{Ti}$ in lattice site $\left(M g_{T i}^{\prime \prime}\right)$. From a simple point of view, the doping reaction by solid $\mathrm{MgO}\left(M g O_{(s)}\right)$ of the stoichiometric $\mathrm{TiO}_{2}$ can be written, in any part of the material, as:

$$
M g O_{(s)} \rightarrow M g_{T i}^{\prime \prime}+O_{O}+V_{O}^{\bullet \bullet}(i)
$$

This underlines that doping with a metal oxide (i.e. ionic doping) does not generate electron excess while defect charges - substitutional $\mathrm{Mg}$ and $\mathrm{O}$ vacancies - are balanced. This corresponds to the second of the above-described mechanism. Mg segregation can also be seen to fully scavenge the excess electrons that result from the preparation of the reduced surface by ion bombardment. Indeed, such a treatment gives rise to oxygen vacancies resulting from their preferential sputtering according to:

$$
O_{O} \rightarrow \frac{1}{2} O_{2(g)}+V_{O}^{\bullet \bullet}+2 e^{\prime}(i i)
$$

leading to excess electrons in superficial layers. During subsequent annealing, a part of the oxygen vacancies may be transformed in interstitial titanium ions with respect to the disappearance of structural units of the crystal according to:

$$
2 V_{O}^{\bullet \bullet}+T i_{T i} \rightarrow T i_{i}^{\bullet \bullet \bullet \bullet}(i i i)
$$

In non-doped titanium oxide, the reoxidation of surface occurs during annealing through diffusion mechanisms which can involve oxygen ions, oxygen vacancies and/or interstitial titanium ions according to reaction (iv) and/or (v) describing diffusion processes and where superscripts indicate whether the species are in surface or bulk areas: 


$$
\begin{aligned}
O_{O}^{\text {bulk }}+V_{O}^{(\text {surf }) \bullet \bullet}+2 e^{(\text {surf })^{\prime}} & \rightarrow V_{O}^{(\text {bulk }) \bullet \bullet}+2 e^{(\text {bulk })^{\prime}}+O_{O}^{\text {surf }}(i v) \\
T i_{i}^{(\text {surf }) \bullet \bullet \bullet}+4 e^{(\text {surf })^{\prime}} & \rightarrow T i_{i}^{(\text {bulk) } \bullet \bullet \bullet}+4 e^{(b u l k)^{\prime}}(v)
\end{aligned}
$$

According to ref ${ }^{52}$ about oxygen-induced restructuring of $\mathrm{TiO}_{2}(110)$ surface, subsurface interstitial titanium ions could be the most labile species making the latter process the most likely one. However, $\mathrm{MgO}$ doping makes possible a third mechanism. According to reaction (i), such a doping requires to consider oxygen vacancies in addition to $\mathrm{Mg}$ atoms substituted to $\mathrm{Ti}$ in lattice site. So, to maintain the electroneutrality of the material, in case of $\mathrm{Mg}$ ion diffusion, the motion of $\mathrm{Mg}$ ions must be accompanied by those of oxygen vacancies. Interdiffusion of magnesium/titanium form bulk/surface to surface/bulk should then be schematized by:

$$
M g_{T i}^{(b u l k)^{\prime \prime}}+V_{O}^{(b u l k) \bullet \bullet}+T i_{T i}^{(\text {surf })}+O_{O}^{(s u r f)} \rightarrow T i_{T i}^{(b u l k)}+O_{O}^{(b u l k)}+M g_{T i}^{(\text {surf })^{\prime \prime}}+V_{O}^{(\text {surf }) \bullet \bullet}(v i)
$$

Besides, Mg diffusion can be concomitant to process (iv), leading to the global reaction (vii):

$$
\begin{gathered}
O_{O}^{(\text {bulk })}+V_{O}^{(\text {bulk }) \bullet \bullet}+M g_{T i}^{(\text {bulk })^{\prime \prime}}+T i_{T i}^{(\text {surf })}+O_{O}^{(\text {surf })}+V_{O}^{(\text {surf }) \bullet \bullet}+2 e^{(\text {surf })^{\prime}} \rightarrow \\
O_{O}^{(\text {bulk })}+V_{O}^{(\text {bulk }) \bullet \bullet}+T i_{T i}^{(\text {bulk })}+2 e^{(\text {bulk })^{\prime}}+M g_{T i}^{(\text {surf })^{\prime \prime}}+O_{O}^{(\text {surf })}+V_{O}^{(\text {surf }) \bullet \bullet}(\text { viii })
\end{gathered}
$$

which can be summed up as a simple interdiffusion of substitutional $\mathrm{Mg}$ and $\mathrm{Ti}$ according to process (ix):

$$
M g_{T i}^{(\text {bulk })^{\prime \prime}}+T i_{T i}^{(\text {surf })}+2 e^{(\text {surf })^{\prime}} \rightarrow 2 e^{(b u l k)^{\prime}}+T i_{T i}^{(\text {bulk })}+M g_{T i}^{(\text {surf })^{\prime \prime}}(i x)
$$

where motions of neither oxygen ions nor oxygen vacancies are necessary to generate it. Such an interdiffusion phenomenon needs a sufficient magnesium mobility, revealed experimentally without ambiguity by the process of segregation itself, as well as the capacity of titanium ions 
to jump from regular sites to interstitial ones (as revealed by ref 52 ) in order to allow the magnesium motion. This process shows that during annealing the excess electrons are simply replaced in surface by substitutional magnesium ions without global moving of oxygen ions and/or vacancies. This leaves to a large amount of oxygen vacancies in surface while the excess electrons have fully diffused in the bulk. Considering the amount of $\mathrm{Mg}$ detected in surface, reaction (vi) appears to be the dominant mechanism. Writing those reactions according to the Kröger and Vink formalism allows to underline that in absence of a large amount of interstitial titanium ions (revealed by PED patterns), the presence of $\mathrm{Mg}$ atoms in the $\mathrm{TiO}_{2}$ topmost layers as substitutional ions entails the global formation of oxygen vacancies in the surface layers without formation of excess electrons, as experimentally demonstrated by the absence of 3d state in band gap (Figure 2(d)) with the support of DFT calculations.

The DFT approach also demonstrates the stability of the structure and composition of the segregated surface layer. Combined with photodiffraction experiments supported by multiple scattering simulations and measured surface concentrations, DFT determines thermodynamically stable structures of given composition $\left(\mathrm{Mg}_{4} \mathrm{Ti}_{3} \mathrm{O}_{10}\right.$, corresponding to $29 \%$ of oxygen vacancies) whose combination corresponds to the surface terminations that are observed. The result is in line with the suggestion by Manzanares et al. ${ }^{13}$ of the formation of a surface compound $\mathrm{MgTiO}_{3}(25 \%$ of oxygen vacancies, a composition close to that found herein) on a $\mathrm{Mg}$-doped $\mathrm{TiO}_{2}$ photocatalyst active in the reduction of $\mathrm{CO}_{2}$.

\section{Conclusions}

A magnesium segregation has been evidenced by annealing the surface of the reduced Mg-doped rutile $\mathrm{TiO}_{2}(011)$ crystal. Combining photoemission to evaluate the composition of the surface region and resonant photoelectron diffraction to feature the sites occupied by $\mathrm{Mg}$ doping elements with DFT simulations to determine the structure of the termination, we arrive at an unambiguous description of the structure and composition of the segregated Mg-rich surface layer, with the 
following characteristics:

- segregated Mg ions are substituted to Ti ions in lattice sites; in parallel, oxygen vacancies are associated to segregated $\mathrm{Mg}$ for charge compensation while the excess electrons accompany the inward diffusion of Ti ions;

- this reoxidation process allows to completely heal the excess electrons from the surface region after annealing at $870 \mathrm{~K}$ as opposed to an undoped surface where such an annealing leaves defect states in the band gap;

- the previously studied surface reconstruction of the pristine $\mathrm{TiO}_{2}(011)$ surface is maintained;

- as determined by DFT, a set of thermodynamically stable structures of given composition represent the Mg-rich surface termination; as a whole, in the surface region, segregated $\mathrm{Mg}$ ions appear to have a higher stability than the polaronic distortions that accompany excess electrons.

The segregation mechanism only involves elementary components, titanium, magnesium and oxygen ions, vacancies and excess electrons. It does not require any specific ingredient from the rutile surface that is examined herein, which suggest that similar processes are likely at work for other aliovalent doping elements (with valence $<4$ ) and surfaces of other titania polymorphs.

\section{Acknowledgement}

Calculations were performed using HPC resources from DNUM CCUB (Centre de Calcul de l'Université de Bourgogne). The authors also thank the ANR for financial support through project ANR-17-EURE-0002 (EIPHI Graduate School). 

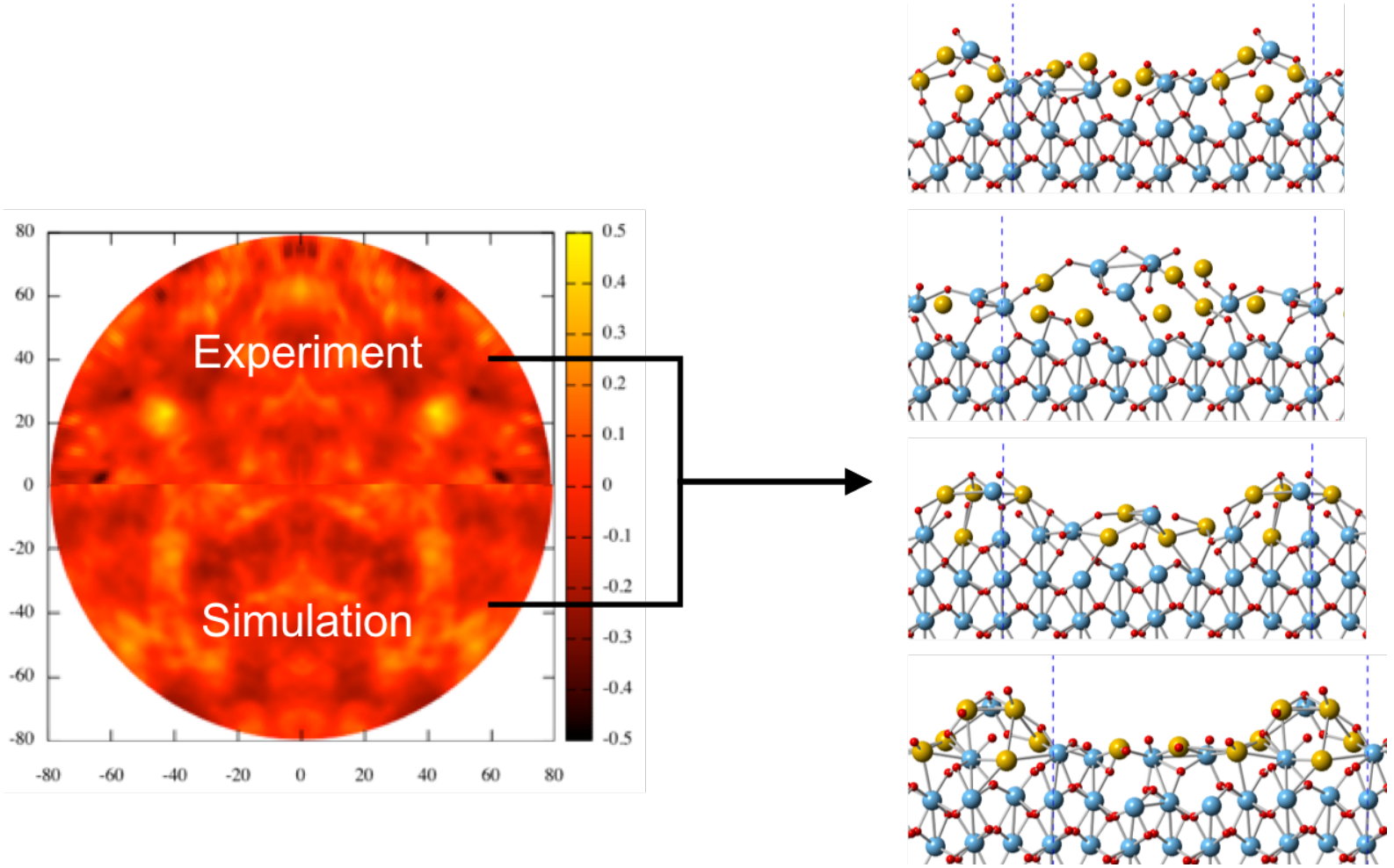

Table of Contents Graphic

\section{References}

(1) Chen, X.; Mao, S. S. Titanium Dioxide Nanomaterials: Synthesis, Properties, Modifications, and Applications. Chem. Rev. 2007, 107, 2891-2959.

(2) Wilke, K.; Breuer, H. Transition Metal Doped Titania: Physical Properties and Photocatalytic Behaviour. Z. Phys. Chem. 1999, 213, 135-140.

(3) Nowotny, M.; Sheppard, L.; Bak, T.; Nowotny, J. Defect Chemistry of Titanium Dioxide. Application of Defect Engineering in Processing of $\mathrm{TiO}_{2}$-Based Photocatalysts. J. Phys. Chem. C 2008, 112, 5275-5300.

(4) Gesenhues, U. Al-doped $\mathrm{TiO}_{2}$ pigments: influence of doping on the photocatalytic degradation of alkyd resins. J. Photochem. Photobiol. A 2001, 139, 243-251. 
(5) Iwamoto, S.; Sazanami, Y.; Inoue, M.; Inoue, T.; Hoshi, T.; Shigaki, K.; Kaneko, M.; Maenosono, A. Fabrication of Dye-Sensitized Solar Cells with an Open-Circuit Photovoltage of 1V. Chem. Sus. Chem. 2008, 1, 401-403.

(6) Zhang, C.; Chen, S.; Mo, L.; Huang, Y.; Tian, H.; Hu, L.; Huo, Z.; Dai, S.; Kong, F.; Pan, X. Charge Recombination and Band-Edge Shift in the Dye-Sensitized $\mathrm{Mg}^{2+}$-Doped $\mathrm{TiO}_{2} \mathrm{Solar}$ Cells. J. Phys. Chem. C 2011, 115, 16418-16424.

(7) Kakiage, K.; Tokutome, T.; Iwamoto, S.; Kyomenac, T.; Hanaya, M. Fabrication of a dye-

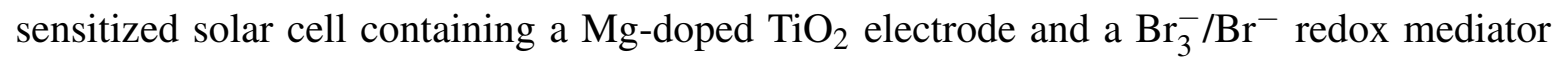
with a high open-circuit photovoltage of 1.21 V. Chem. Commun. 2013, 49, 179-180.

(8) Liu, Q. Photovoltaic Performance Improvement of Dye-Sensitized Solar Cells Based on MgDoped $\mathrm{TiO}_{2}$ Thin Films. Electrochim. Acta 2014, 129, 459-462.

(9) Manseki, K.; Ikeya, T.; Tamura, A.; Ban, T.; Sugiuraa, T.; Yoshida, T. Mg-doped TiO 2 nanorods improving open-circuit voltages of ammonium lead halide perovskite solar cells. RSC Adv. 2014, 4, 9652-9655.

(10) Pathak, S.; Abate, A.; Ruckdeschel, P.; Roose, B.; Gödel, K.; Vaynzof, Y.; Santhala, A.; Watanabe, S.-I.; Hollman, D.; Noel, N.; Sepe, A.; Wiesner, U.; Friend, R.; Snaith, H.; Steiner, U. Performance and Stability Enhancement of Dye-Sensitized and Perovskite Solar Cells by Al Doping of $\mathrm{TiO}_{2}$. Adv. Func. Mater. 2004, 24, 6046-6055.

(11) Wang, J.; Qin, M.; Tao, H.; Ke, W.; Chen, Z.; Wan, J.; Qin, P.; Xiong, L.; Lei, H.; Yu, H.; Fang, G. Performance enhancement of perovskite solar cells with Mg-doped $\mathrm{TiO}_{2}$ compact film as the hole-blocking layer. App. Phys. Lett. 2015, 106, 121104/1-121104/5.

(12) Koketsu, T.; Ma, J.; Morgan, B. J.; Body, M.; Legein, C.; Dachraoui, W.; Giannini, M.; Demortière, A.; Salanne, M.; Dardoize, F.; Groult, H.; Borkiewicz, O. J.; Chapman, K. W.; Strasser, P.; Dambournet, D. Reversible magnesium and aluminium ions insertion in cationdeficient anatase $\mathrm{TiO}_{2}$. Nat. Mat. 2017, 16, 1142-1148. 
(13) Manzanares, M.; Fàbrega, C.; Ossó, J.; Vega, L. F.; Andreu, T.; Morante, J. R. Engineering the $\mathrm{TiO}_{2}$ outermost layers using magnesium for carbon dioxide photoreduction. App. Catal. B. Env. 2014, 150, 57-62.

(14) Sofianou, M.-V.; Tassi, M.; Boukos, N.; Thanos, S.; Vaimakis, T.; Yu, J.; Trapalis, C. Solvothermal synthesis and photocatalytic performance of $\mathrm{Mg}^{2+}$-doped anatase nanocrystals with exposed $\{001\}$ facets. Catal. Tod. 2014, 230, 125-130.

(15) Venkatachalam, N.; Palanichamy, M.; Murugesan, V. Sol-gel preparation and characterization of alkaline earth metal doped nano $\mathrm{TiO}_{2}$ : Efficient photocatalytic degradation of 4chlorophenol. J. Mol. Cat. A 2007, 273, 177-185.

(16) Segne, T.; Tirukkovalluri, S.; Challapalli, S. Studies on Characterization and Photocatalytic Activities of Visible Light Sensitive $\mathrm{TiO}_{2}$ Nano Catalysts Co-doped with Magnesium and Copper. Int. Res. J. Pure Appl. Chem. 2011, 1, 84-103.

(17) Islam, M.; Bredow, T.; Gerson, A. Electronic properties of oxygen-deficient and aluminumdoped rutile $\mathrm{TiO}_{2}$ from first principles. Phys. Rev. B 2007, 76, 045217/1-045217/9.

(18) Shirley, R.; Kraft, M.; Inderwildi, O. Electronic and optical properties of aluminium-doped anatase and rutile $\mathrm{TiO}_{2}$ from ab initio calculations. Phys. Rev. B 2010, 81, 075111/1$075111 / 9$.

(19) Shannon, R. Revised effective ionic radii and systematic studies of interatomic distances in halides and chalcogenides. Acta Cryst. A 1976, 32, 751-767.

(20) Thompson, T.; Yates, J. Surface science studies of the photoactivation of $\mathrm{TiO}_{2}$-new photochemical processes. Chem. Rev. 2006, 106, 4428-4453.

(21) Li, J.; Lazzari, R.; Chenot, S.; Jupille, J. Contributions of oxygen vacancies and titanium interstitials to band-gap states of reduced titania. Phys. Rev. B 2018, 97, 041403/1-041403/5. 
(22) Henrich, V.; Dresselhaus, G.; Zeiger, H. Observation of Two-Dimensional Phases Associated with Defect States on the Surface of $\mathrm{TiO}_{2}$. Phys. Rev. Lett. 1976, 36, 1335-1339.

(23) Kurtz, R.; Stockbauer, R.; Madey, T.; Roman, E.; de Segovia, J. Synchrotron radiation studies of $\mathrm{H}_{2} \mathrm{O}$ adsorption on $\mathrm{TiO}_{2}$ (110). Surf. Sci. 1989, 218, 178-200.

(24) Zhang, Z.; Jeng, S.; Henrich, V. Cation-ligand hybridisation for stoichiometric and reduced $\mathrm{TiO}_{2}(110)$ surfaces determined by resonant photoemission. Phys. Rev. B 1991, 43, 1200412011.

(25) Patel, R.; Guo, Q.; Coks, I.; Williams, E.; Roman, E.; de Segovia, J. The defective nature of the $\mathrm{TiO}_{2}(110)(1 \times 2)$ surface. J. Vac. Sci. Technol. A 1997, 15, 2553-2556.

(26) Sekiya, T.; Yagisawa, T.; Kamiya, N.; Das Mulmi, D.; Kurita, S.; Murakami, Y.; Kodaira, T. Defects in anatase $\mathrm{TiO}_{2}$ single crystal controlled by heat treatments. J. Phys. Soc. Jpn. 2004, $73,703-710$.

(27) Ganduglia-Pirovano, M. V.; Hofmann, A.; Sauer, J. Oxygen vacancies in transition metal and rare earth oxides: Current state of understanding and remaining challenges. Surf. Sci. Rep. 2007, 62, 219-270.

(28) Saponjic, Z.; Dimitrijevic, N.; Poluektov, O.; Chen, L.; Wasinger, E.; Welp, U.; Tiede, D.; Zuo, X.; Rajh, T. Charge Separation and Surface Reconstruction: A Mn ${ }^{2+}$ Doping Study. J. Phys. Chem. B 2006, 110, 25441-25450.

(29) Gionco, C.; Livraghi, S.; Maurelli, S.; Giamello, E.; Tosoni, S.; Valentin, C. D.; Pacchioni, G. Al- and Ga-Doped $\mathrm{TiO}_{2}, \mathrm{ZrO}_{2}$, and $\mathrm{HfO}_{2}$ : The Nature of $\mathrm{O} 2 \mathrm{p}$ Trapped Holes from a Combined Electron Paramagnetic Resonance (EPR) and Density Functional Theory (DFT) Study. Chem. Mat. 2015, 27, 3936-3945.

(30) Zainullina, V.; Zhukov, V.; Korotin, M. Influence of oxygen nonstoichiometry and doping with $2 \mathrm{p}-, 3 \mathrm{p}-, 6 \mathrm{p}-$ and $3 \mathrm{~d}-\mathrm{elements}$ on electronic structure, optical properties and photocat- 
alytic activity of rutile and anatase: Ab initio approaches. J. Photochem. Photobiol. C 2015, $22,58-83$.

(31) Krüger, P.; Bourgeois, S.; Domenichini, B.; Magnan, H.; Chandesris, D.; Fèvre, P. L.; Flank, A. M.; Jupille, J.; Floreano, L.; Cossaro, A.; Verdini, A.; Morgante, A. Defect States at the $\mathrm{TiO}_{2}(110)$ Surface Probed by Resonant Photoelectron Diffraction. Phys. Rev. Lett. 2008, $100,055501 / 1-055501 / 4$.

(32) Krüger, P.; Jupille, J.; Bourgeois, S.; Domenichini, B.; Verdini, A.; Floreano, L.; Morgante, A. Intrinsic Nature of the Excess Electron Distribution at the $\mathrm{TiO}_{2}(110)$ Surface. Phys. Rev. Lett. 2012, 108, 126803/1-126803/4.

(33) Dupont, C.; Bourgeois, S.; Fèvre, P. L.; Verdini, A.; Floreano, L.; Domenichini, B. Structure of $\mathrm{TiO}_{2}$ (011) revealed by photoelectron diffraction. Phys. Rev. B 2016, 94, 241304/1$241304 / 6$.

(34) Danger, J.; Fèvre, P. L.; Magnan, H.; Chandesris, D.; Bourgeois, S.; Jupille, J.; Eickhoff, T.; Drube, W. Quadrupolar Transitions Evidenced by Resonant Auger Spectroscopy. Phys. Rev. Lett. 2002, 88, 243001/1-243001/4.

(35) Le Fèvre, P.; Danger, J.; Magnan, H.; Chandesris, D.; Jupille, J.; Bourgeois, S.; Arrio, M.; Gotter, R.; Verdini, A.; Morgante, A. Stoichiometry-related Auger lineshapes in titanium oxides: Influence of valence-band profile and of Coster-Kronig processes. Phys. Rev. B 2004, $69,155421 / 1-155421 / 9$.

(36) Le Fèvre, P.; Magnan, H.; Chandesris, D.; Jupille, J.; Bourgeois, S.; Drube, W.; Ogasawarag, H.; Uozumih, T.; Kotanihij, A. Interpretation of absorption edges by resonant electronic spectroscopy: experiment and theory. J. Electron Spectro. Relat. Phenom. 2004, 136, $37-47$.

(37) Floreano, L.; Naletto, G.; Cvetko, D.; Gotter, R.; Malvezzi, M.; Marassi, L.; Morgante, A.; Santaniello, A.; Verdini, A.; Tommasini, F.; Tondello, G. Performance of the grating-crystal 
monochromator of the ALOISA beamline at the Elettra Synchrotron. Rev. Sci. Instr. 1999, $70,3855-3864$.

(38) Yeh, J.; Lindau, I. Atomic subshell photoionization cross sections and asymmetry parameters: $1 \leq \mathrm{Z} \leq 103$. At. Data Nucl. Data Tables 1985, 32, 1-155.

(39) Bruno, F.; Floreano, L.; Verdini, A.; Cvetko, D.; Gotter, R.; Morgante, A.; Canepa, M.; Terreni, S. Study of the isotropic contribution to the analysis of photoelectron diffraction experiments at the ALOISA beamline. J. Electron Spectro. Relat. Phenom. 2002, 127, 8592.

(40) Oganov, A.; Glass, C. Crystal structure prediction using ab initio evolutionary techniques: Principles and applications. J. Chem. Phys. 2006, 124, 244704/1-244704/15.

(41) Oganov, A.; Lyakhov, A.; Valle, M. How Evolutionary Crystal Structure Prediction Worksand Why. Acc. Chem. Res. 2011, 44, 227-237.

(42) Lyakhov, A.; Oganov, A.; Stokes, H.; Zhu, Q. New developments in evolutionary structure prediction algorithm USPEX. Comput. Phys. Commun. 2013, 184, 1172-1182.

(43) Zhu, Q.; Li, L.; Oganov, A.; Allen, P. Evolutionary method for predicting surface reconstructions with variable stoichiometry. Phys. Rev. B 2013, 87, 195317/1-195317/8.

(44) Kresse, G.; Hafner, J. Abinitio molecular-dynamics for liquid-metals. Phys. Rev. B 1993, 47, $558-561$.

(45) Kresse, G.; Furthmüller, J. Efficient iterative schemes for ab initio total-energy calculations using a plane-wave basis set. Phys. Rev. B 1996, 54, 11169-11186.

(46) Perdew, J.; Burke, K.; Ernzerhof, M. Generalized gradient approximation made simple. Phys. Rev. Lett. 1996, 77, 3865-3868. 
(47) Dudarev, S.; Botton, G.; Savrasov, S.; Humphreys, C.; Sutton, A. Electron-energy-loss spectra and the structural stability of nickel oxide: An LSDA+U study. Phys. Rev. B 1998, 57, 1505-1509.

(48) Pack, J.; Monkhorst, H. Special points for Brillouin-zone integrations"—a reply. Phys. Rev. B 1977, 16, 1748-1749.

(49) de Abajo, F. J. G.; Van Hove, M. A.; Fadley, C. S. Multiple scattering of electrons in solids and molecules: A cluster-model approach. Phys. Rev. B 2001, 63, 075404/1-075404/16.

(50) Corneille, J.; He, J.-W.; Goodmann, D. XPS characterization of ultra-thin MgO films on a Mo(100) surface. Surf. Sci. 1994, 306, 269-278.

(51) Pétigny, S.; Mostéfa-Sba, H.; Domenichini, B.; Lesniewska, E.; Steinbrunn, A.; Bourgeois, S. Superficial defects induced by argon and oxygen bombardments on (110) $\mathrm{TiO}_{2}$ surfaces. Surf. Sci. 1998, 410, 250-257.

(52) Henderson, M. A. A surface perspective on self-diffusion in rutile $\mathrm{TiO}_{2}$. Surf. Sci. 1999, 419, $174-187$.

(53) Yurtsever, A.; Onoda, J.; Abe, M.; Pang, C.; Sugimoto, Y. Imaging the $\mathrm{TiO}_{2}(011)-(2 \times 1)$ Surface using Noncontact Atomic Force Microscopy and Scanning Tunneling Microscopy. $J$. Phys. Chem. C 2016, 120, 3390-3395.

(54) Kröger, F.; Vink, H. Relations between the Concentrations of Imperfections in Crystalline Solids. Solid State Physics 1956, 3, 307-435. 